\title{
MISS NIGHTINGALE'S HEADQUARTERS
}

\author{
Colonel R. L. BELL,
}

\author{
M.R.C.S., L.R.C.P., M.F.C.M., D.P.H., D.I.H., D.T.M.\&H., late R.A.M.C. \\ Mrs. R. L. BELL, S.R.N.
}

ScUTARI is the city on the Asiatic side of the Bosphorus opposite the European city of Instanbul. Here, in Selimye Barracks, Florence Nightingale established modern military nursing.

We recently spent a holiday in Instanbul and visited the Barracks, now the Headquarters of the 1st Army. It is a huge building in the shape of a hollow rectangle, about 280 yards by 240 yards. The corridors are wide and the rooms high and spacious; comfortable in the heat of summer but chilly, one imagines, in winter. An extremely smart English-speaking subaltern was detailed by the orderly officer to escort us to Miss Nightingale's rooms in the second and third stories of the Tower at the NorthWest corner (Fig. 1.), little changed since she had lived there. Her office, or study, is

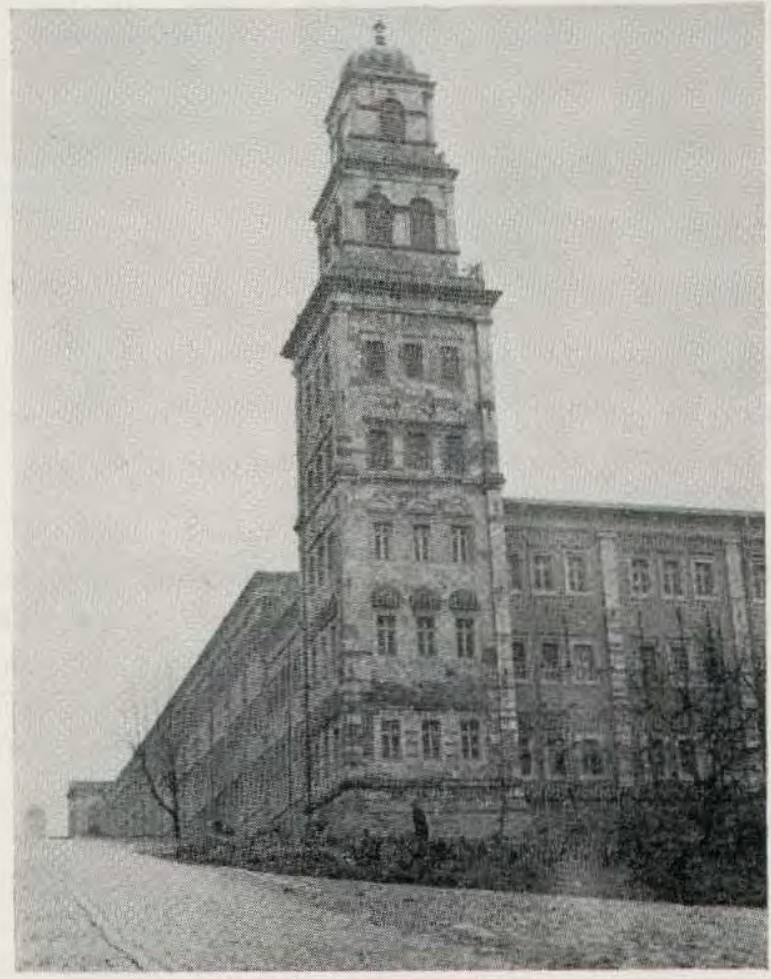

Fig. 1. The North-West Tower of Selimye Barracks.

spartanly furnished with a knee-hole desk and chair, a brass candlestick, a Turkish inkwell and pen-stand, a table and a lamp. It is too much to believe that it is "The Lamp "; it is without any doubt of the same pattern. Artists usually portray Miss Nightingale's lamp as resembling a stage-property in a pantomime "Aladdin" but as 
the photographs show (Figs 2 and 3 ) it is very different; a very sensible form of stormcandlestick with a concertina of stiff paper which pulls up to protect the flame from draughts.

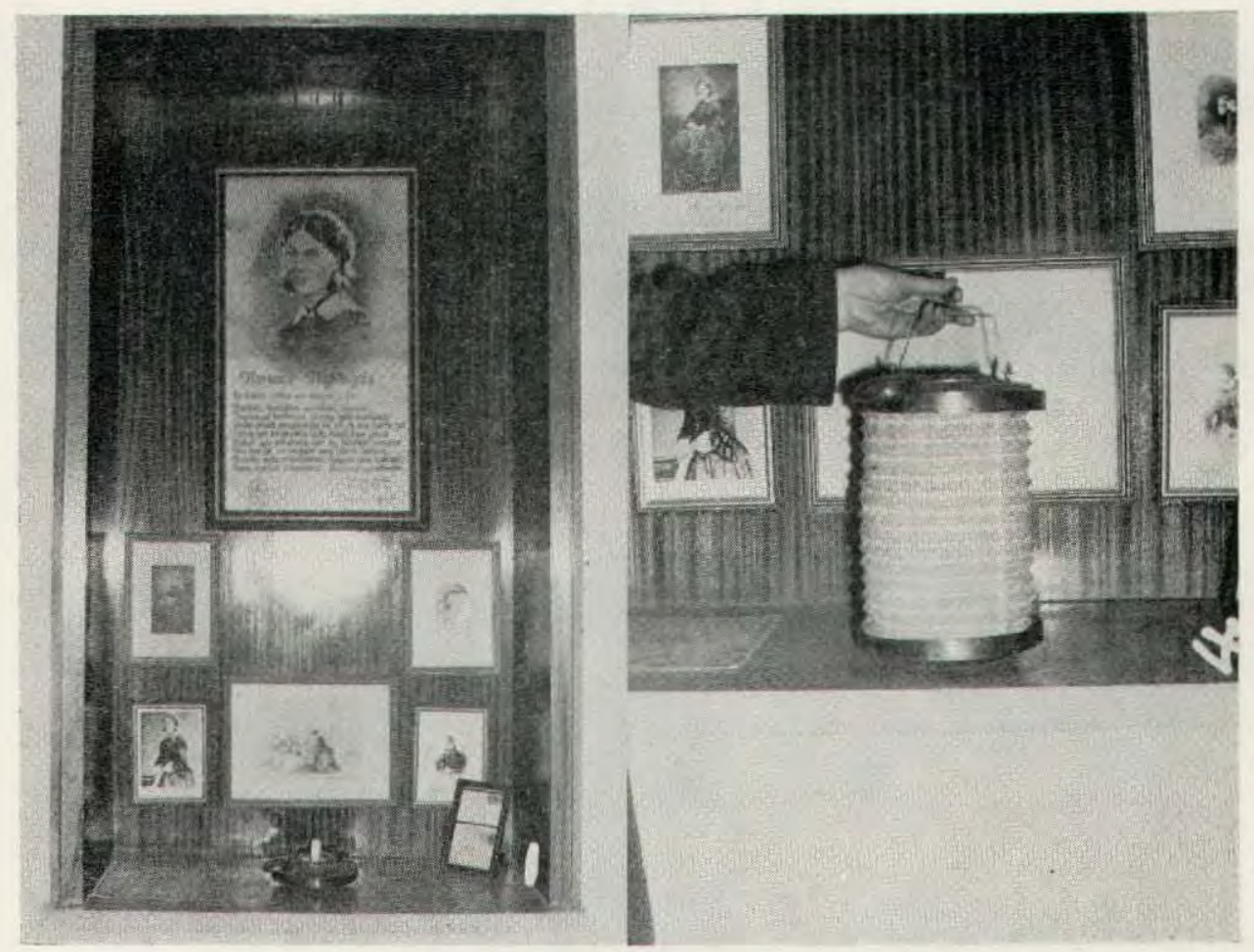

Figs. 2 and 3. The lamp open (left) and closed for carriage (right).

On the walls are numerous engravings and reproductions of paintings concerning the Nightingale family and the hospital services during the Crimean War. Also displayed are many of her treatises on medical and nursing subjects, all with good strong titles such as "Notes on Nursing for the Labouring Classes ", " The Organisation of Nursing ", "Lying-in Institutes" and " How People may Live not Die in India".

A simple modern spiral staircase rises from the middle of the study and connects it to the bed-sitting room above. This is in the same position and of the same size as the original which was removed as unsafe quite recently. On the rails supporting the banister are displayed a charming collection of sketches of the wards, corridors and messes of the Hospital as it was during the Crimean War, all by members of the staff at the time.

At the top of the stairs is the bed-sitting room, well kept and still having the air of a favourite private room. Only a few pieces of furniture remain: a Victorian oval walnut table and four dining chairs and a large and comfortable divan. This is quite 9 foot long and 3 foot wide and is covered with a pretty sprigged material with plump back-cushions to match. Displayed on the cushions are old Turkish towels, narrow hand-woven linen cloths decorated at each end with bands of embroidery in bright colours 
and silver and gold thread. These designs are traditional and Miss Nightingale must have been familiar with them. The curtains are chestnut brown with a bobble fringe to match.

The most striking picture in the room is a large reproduction of a double portrait of Miss Nightingale and her sister Parthena as young girls, wearing simple muslın dresses, holding pieces of needlework and posed against rich draperies. " Daughters at Home "; such a contrast to the busy life of Selimye Barracks.

The view from the tower is superb. The domes and minarets of Instanbul's old city are directly across the Bosphorus. The waterway itself is busy with shipping of all sizes and vintages and a never-ending delight (Fig. 4). The North window looks down

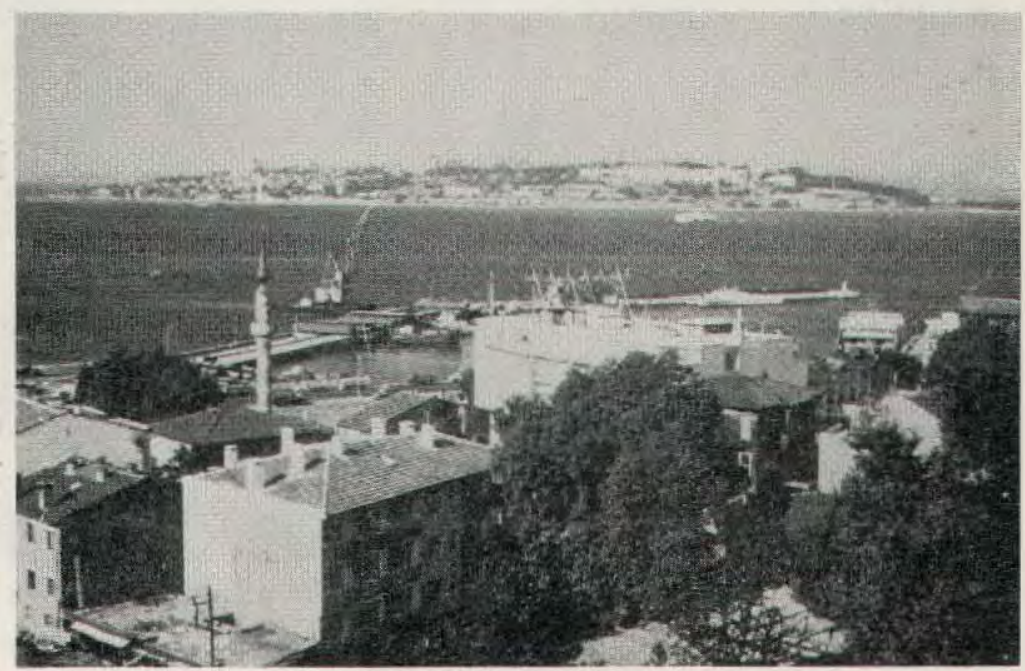

Fig. 4. View of Instanbul from the bedroom window.

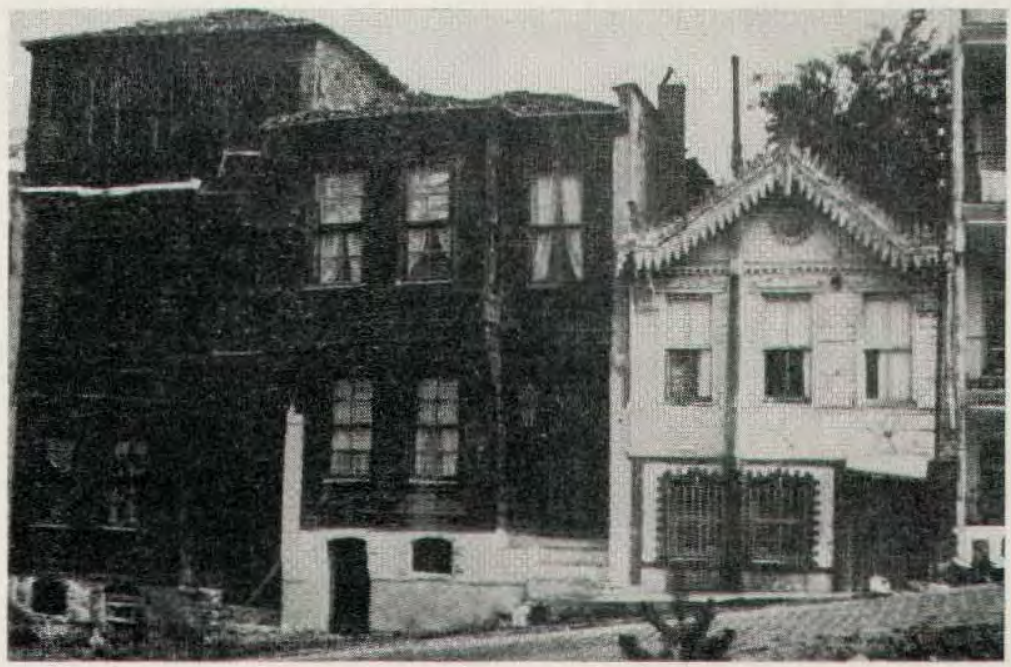

Fig. 5. View of old Scutari from the study window. 
on a piece of old Scutari, wooden town-houses exactly as they were in Miss Nightingale's day (Fig. 5).

The shrine, for one cannot call it less, is maintained with loving care. The strength of the Nightingale image is amply illustrated by the plaque erected in her rooms by the "Turkish Nursing Association" (Fig. 6). This, translated, reads "This tower was the cradle of modern nursing, founded by Florence Nightingale in 1854-1856".

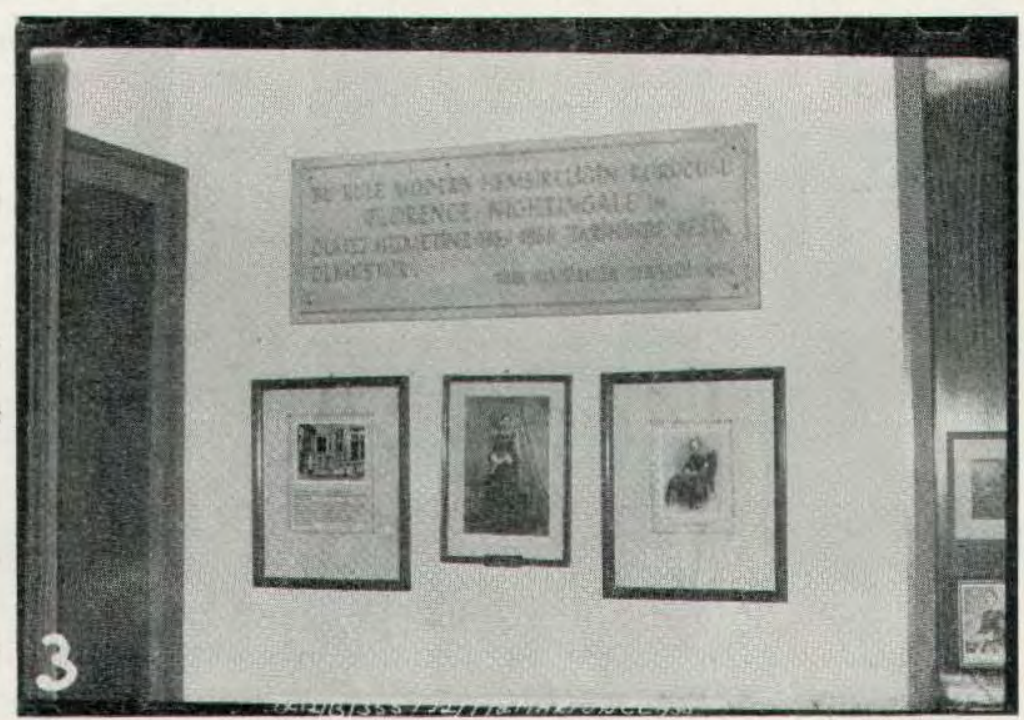

Fig. 6. The plaque erected in Miss Nightingale's rooms by the Turkish Nursing Association.

\section{Acknowledgements}

Our thanks are due to the Turkish Army for its courtesy and help and to Brigadier D. S. Sole, C.V.O., O.B.E., formerly Defence and Military Attaché, Ankara, for his help and most of the photographs. 